\title{
$x+5$
}

NASA Technical Memorandum 106222

AIAA-93-2403

$1 N-20$

171946

$P 27$

\section{Preliminary Endurance Tests of Water Vaporizers for Resistojet Applications}

W.Earl Morren and Gregory S. MacRae

Lewis Research Center

Cleveland, Ohio

Prepared for the

29th Joint Propulsion Conference and Exhibit cosponsored by the AIAA, SAE, ASME, and ASEE

Monterey, California, June 28-30, 1993

(NASA-TM-106222) PRELIMINARY

ENDURANCE TESTS OF WATER VAPORIZERS

FOR RESISTOJET APPLICATIONS (NASA)

$27 \mathrm{p}$
N93-28694

Unclas 



\title{
Preliminary Endurance Tests of Water Vaporizers for Resistojet Applications
}

\author{
W. Earl Morren \\ and \\ Gregory S. MacRae \\ National Aeronautics and Space Administration \\ Lewis Research Center \\ Cleveland, $\mathrm{OH}$
}

\begin{abstract}
Three water vaporizers designed for resistojet applications were built and tested for periods up to $500 \mathrm{~h}$ and 250 thermal cycles. Two of the vaporizers were not sensitive to orientation with respect to gravity, an indication of likely compatibility with low-gravity environments. Some temperatures and pressures in the third were impacted by orientation, although operation was always stable. The pressure drop across the sand-filled version increased by 147 percent in $38 \mathrm{~h}$ and 19 thermal cycles. Bonding of the sand granules in the downstream end of the heat exchanger was the suspected cause of failure of this vaporizer. Pressure drops across two sintered stainless steel-filled versions were more gradual. One, with a pore size of $60 \mu \mathrm{m}$, showed an 80 percent increase in $500 \mathrm{~h}$ and 250 thermal cycles and another, with a $10 \mu \mathrm{m}$ pore size, showed a 29 percent increase in $350 \mathrm{~h}$ and 175 thermal cycles. Testing of the latter metal-filled vaporizer was ongoing as of this writing. Oxidation of the porous metal packing materials in these vaporizers, with subsequent deposition of oxide particles within the pores, was believed to have caused the observed increases in pressure drops.
\end{abstract}

\section{INTRODUCTION}

Resistojets capable of operating on water propellant have been considered for stationkeeping for various spacecraft, including the Manned Orbital Research Laboratory (MORL) ${ }^{1}$ and the Industrial

Copyright 01993 by the Anetican Inatituke of Aeronantics and Astronantics, Inc. No copyright is aserted in the Uniled Stales under Tille 17 , U.S. Cade. The U.S. Govermment has a royalty-free license to exercise all rights under the
copyright claimed berein for Governmental porposes. All ober rights are copyright claimed berein for
reserved by the copyright owner.
Space Facility (ISF) ${ }^{2}$. More recently, water resistojets were considered for drag cancellation on Space Station Freedom (SSF). Benefits of water resistojets include propellant handling safety and the potential for propulsive use of waste water, such as shuttle fuel cell effluent. These benefits were considered in a recent study of SSF propulsion system options ${ }^{3}$. 
In water resistojets the propellant must be actively vaporized prior to expansion through a nozzle. Rapid expansion of liquid water to a vacuum causes freezing which could plug the nozzle and result in thruster failure. Therefore, water resistojet systems must include a water vaporizer capable of operation in low gravity. Considerable effort has been expended toward water resistojet vaporizer technology. Various vaporizer concepts have been built and tested, both alone and integrated with resistojets ${ }^{4-8}$, and power control concepts have been investigated ${ }^{5,7-9}$. Sensitivity to gravity effects has been investigated on the ground $4,7,8$ and in low-gravity aircraft flight tests 8 . Details of these efforts are summarized in Refs. 7 and 8.

Technology programs to date have demonstrated the ability to reliably, controllably, and efficiently vaporize water at flow rates of interest for resistojet applications. Compatibility of some concepts with low-gravity environments appears likely ${ }^{8}$. However, life evaluations of resistojet water vaporizers have not been conducted. Vaporizer life requirements have not been specified, but the engineering model multipropellant resistojet ${ }^{10}$ developed under the Space Station Propulsion Advanced Development Program was designed for $10^{4} \mathrm{~h}$ of operation. Therefore, endurance tests of several thousands of hours are likely essential to validate vaporizer life. As a first step toward this goal, this paper presents the results of cyclic endurance tests of three packed-bed water vaporizers. The sandfilled vaporizer described in Ref. 8 and two similar, sintered metal-filled vaporizers were operated for periods up to $500 \mathrm{~h}$ and 250 thermal cycles. Issues of fluid/material compatibility are discussed. Histories of critical operating parameters are presented, and recommendations for vaporizer design improvements and further tests are made.

\section{APPARATUS AND PROCEDURE}

\section{Vaporizer}

The design details of the sand-filled vaporizer and test apparatus are presented in a companion paper ${ }^{8}$, but are repeated here for the reader's convenience. Differences between the two metal-filled vaporizers and the one tested for Ref. 8 are also described. Design goals for all three vaporizers were to stably and reliably produce slightly superheated vapor at flow rates and outlet pressures of $100 \times 10^{-6}$ to $250 \times 10^{-6} \mathrm{~kg} / \mathrm{s}$ and 200 to $500 \mathrm{kPa}$, respectively. These conditions span the likely range of interest for resistojet applications.

Figure 1 shows a sectional view of the sand-filled water vaporizer, designated SNO02. The overall configuration consisted of a centrally-located heater surrounded by an annular heat exchanger filled with sand. 
This configuration was chosen because it was simple to fabricate and assemble, allowed access to the heat exchanger for temperature measurements, and because the majority of heat dissipated by the heater had to travel through the water which tended to minimize thermal losses. Liquid was fed to the vaporizer through four $1.6 \mathrm{~mm}$ o.d. tubes evenly spaced about the annulus. A circular channel of $1.6 \mathrm{~mm}$ square cross section on the inside of the inlet end cap aided distribution of the incoming liquid about the annulus. A filter made from sintered stainless steel with a $5 \mu \mathrm{m}$ pore size (chosen for convenience) prevented sand from blocking the feed tubes. The heater was a commercially-available unit, $102 \mathrm{~mm}$ long by $12.7 \mathrm{~mm}$ dia., rated at 750 $\mathrm{W}$ at $120 \mathrm{~V}$, and comprised a nickelchromium alloy filament, ceramic insulation, and inconel sheath. A Type- $K$ thermocouple ( $T_{h}$ in Fig. 1) was embedded in the insulation on axis at the center of the heater cartridge. Four banks of three Type$\mathrm{K}$ thermocouples each $\left(T_{b 1}\right.$ through $T_{b 12}$ in Fig. 1) were located in line with the liquid inlets with junctions located at the radial midpoint of the annulus. The heat exchanger shell was made from stainless steel tubing $102 \mathrm{~mm}$ long with $25.4 \mathrm{~mm}$ o.d. and $1.65 \mathrm{~mm}$ wall thickness. Superheated vapor exited the heat exchanger through an outlet tube $41 \mathrm{~mm}$ long with $12.7 \mathrm{~mm}$ o.d. and $7.95 \mathrm{~mm}$ i.d. A filter made from four layers of 5-mesh stainless steel screen plus one layer of 50- mesh stainless steel screen contained the sand at the end of the outlet tube. This screen pack replaced the sintered stainless steel filter used for the Ref. 8 tests, since that filter was found to be responsible for 47 percent of the vaporizer pressure drop during those tests. The heat exchanger was filled through the outlet tube after the thermocouple probes were inserted. The heat exchanger was rotated and vibrated during filling to assure no voids formed in the sand. The volume of sand added was compared to the estimated heat exchanger volume to further ensure it was full.

Figure 2 shows a sectional view of the porous metal-filled vaporizers. The bed packing materials, numbers of feed tubes, and numbers of thermocouples all differed from SN002. The metal-filled heat exchangers were packed with sintered type 304L stainless steel. Vaporizers with packing pore sizes of $10 \mu \mathrm{m}$ and $60 \mu \mathrm{m}$ were designated SNOO4 and SNO05, respectively. The sintered metal packings were solid porous media, unlike the sand in SN002. Therefore, SNO04 and SNOO5 required no inlet or outlet filters to contain the packings, and the shapes of the porous heat exchanger paths differed from $\mathrm{SNO} 02$. The metal-filled vaporizers had no packings in the outlet tubes. The sand-filled outlet tube was identified in Ref. 8 as being responsible for 84 percent of the pressure drop through the heat exchanger (excluding the outlet filter) of SNOO2. Both SNOO4 
and SNOO5 had only one liquid feed tube and one bank of three Type- $K$ thermocouples (Tb1 through Tb3 in Fig. 2) embedded in the heat exchangers. The thermocouples were separated from the feed tubes azimuthally by $180^{\circ}$. This was, in fact, the original configuration of SN002, but additional thermocouples and feed tubes were added to that unit prior to the Ref. 8 tests. Time constraints prevented similar modifications to SNO04 and SN005. Table I summarizes the differences between the three vaporizers tested.

\section{Test Apparatus}

All tests were conducted using the apparatus constructed for the gravity sensitivity tests reported in Ref. 8. Figure 3 shows a schematic diagram of that apparatus. Liquid was fed to the vaporizer from a reservoir with a piston and O-ring. The flow rate through the system was changed by adjusting the pressure applied to the reservoir from a regulated gas supply. The flow rate was determined by measuring the pressure drop of the water flowing through a commercially-available fluid resistor. The pressure of the liquid feedwater was measured between the fluid resistor and the vaporizer. The vaporizer exhausted into a small plenum where effluent pressure and temperature were measured. An orifice $0.74 \mathrm{~mm}$ in diameter simulated a resistojet.
For an SSF application, the potable water supply is a likely source of propellant. Therefore, water used for these tests was conditioned to approximate the quality of SSF potable water. Propellant water was obtained from an aeration-type laboratory cooling water supply. The water was purified using a commercially-available deionization system. Since the deionization system could not remove dissolved gases, the feed water was likely to have been saturated with air at ambient temperature (about $10^{\circ} \mathrm{C}$ ) and atmospheric pressure. No attempt was made to degas the water, although the SSF water recovery system does include a degasser. The deionized water was passed through a flight-type microbial check valve, which added approximately $4 \mathrm{ppm}$ of iodine to conform to Shuttle Orbiter and SSF potable water specifications. Water samples were obtained at the deionization system outlet and vaporizer inlet and analyzed for $\mathrm{pH}$, conductivity, and concentrations of iodine, and selected metals.

Power was supplied to the heater from a laboratory power supply capable of providing up to $150 \mathrm{Vdc}$ at up to $12 \mathrm{~A}$. This power supply replaced the pulse width-modulated power controller used for the Ref. 8 tests to simplify heater voltage and current signal diagnostics. Heater voltage was modulated to regulate the ratio of power to flow rate (specific power) at 
approximately $3.0 \mathrm{MJ} / \mathrm{kg}$. Test conditions were monitored and heater power was controlled using a microcomputer-based data acquisition and control unit (DACS). Table II summarizes the parameters monitored.

\section{Steady State Tests}

A brief series of tests was conducted to characterize steady state performance of the vaporizers to assure that they met the design goals. For these tests the vaporizers were each started cold and full of water (flooded) at feed pressures of 700,1400 , 2100 , and $2800 \mathrm{kPa}$. These feed pressures produced flow rates which spanned the range of interest. Data were recorded after $20 \mathrm{~min}$ of operation at each setpoint.

\section{Gravity Sensitivity Tests}

Results presented in Ref. 8 showed that the insensitivity of SNOO2 to orientation with respect to gravity in ground tests was a fair indicator of compatibility with a lowgravity environment, as demonstrated in aircraft tests. Therefore, SNOO4 and SN005 were operated in various orientations with respect to gravity. Each vaporizer was started cold and flooded at a feed pressure and specific power of 2100 $\mathrm{kPa}$ and $3.0 \mathrm{MJ} / \mathrm{kg}$, respectively, in a vertical-axis position with the liquid fed to the top (upright position). The vaporizer was rotated $90^{\circ}$ about a horizontal axis normal to its own every $20 \mathrm{~min}$ to horizontal and inverted positions before being returned to the upright position. This provided sufficient time for the vaporizer to reach steady operation in each position before being moved to the following position. Operating conditions were recorded every $2 \mathrm{~s}$ during these tests.

\section{Endurance Tests}

Operational life requirements for resistojet water vaporizers could be on the order of several thousand hours. The current tests sought to identify life limiting issues through brief tests of a few vaporizers. The goals for these endurance tests were to complete $500 \mathrm{~h}$ and 250 thermal cycles on each vaporizer. These test durations were felt appropriate for preliminary life tests to identify those design and operational issues which should be addressed prior to fullscale life testing.

Each vaporizer was operated on cycles of 2 h, $10 \mathrm{~min}$ period. The feed pressure and specific power were regulated at $2100 \mathrm{kPa}$ and $3.0 \mathrm{MJ} / \mathrm{kg}$, respectively. Each thermal cycle began by flowing water through the cold vaporizer for $1 \mathrm{~min}$ to assure the heat exchanger was flooded. Power was applied for $2 \mathrm{~h}$, following which flow was maintained without power for $5 \mathrm{~min}$ to cool the vaporizer. The reservoir pressurant was then vented, allowing deionized, iodized water to refill the reservoir through a check valve. It is important to note that, in a flight application, the vaporizer would be 
evacuated through the resistojet and cooled radiatively between firings. Therefore it would be empty, not flooded, at start-up. The impacts on vaporizer life of the differences between a flight operating scenario and the test method used are not known. A dedicated endurance test facility which will better simulate the on-orbit operating environment is under construction, but was unavailable for these tests.

\section{Post-Test Inspections}

Following their respective tests, $\mathrm{SNO} 02$ and SN005 were disassembled for inspection. Samples of the sand from SNO02 were removed from thermocouple ports $T_{b 1}$ and $T_{b 3}$ for elemental analysis using inductively-coupled plasma (ICP) emission spectroscopy. The SNOO2 heat exchanger was also sectioned for visual inspection. The SNOO5 heat exchanger was sectioned to permit removal of the sintered metal packing. Samples of this material were analyzed using ICP spectroscopy. Outer surfaces and cross sections were examined by scanning electron microscopy (SEM). The heat exchanger shell and heater were also visually examined. The SNOO4 test was ongoing as of this writing, so it was not disassembled.

\section{RESULTS AND DISCUSSION}

The objective of this work was to rapidly identify life issues for resistojet water vaporizers. The vaporizers were designed to provide superheated vapor stably and repeatably at flow rates and outlet pressures of $100 \times 10^{-6}$ to $250 \times 10^{-6} \mathrm{~kg} / \mathrm{s}$ and 200 to $500 \mathrm{kPa}$, respectively. Three vaporizers were evaluated for periods up to $500 \mathrm{~h}$ and 250 thermal cycles at fixed feed pressures and specific power levels. This section compares the steady state characteristics, effects of orientation with respect to gravity, and histories of critical operating parameters for each of the endurance tests. Observations made during post-test disassemblies are discussed and results of analyses conducted are presented. Recommendations for vaporizer and system design modifications and test procedure changes are also made.

\section{Steady State Performance}

Steady state tests were conducted to validate stable and repeatable operation over the range of flow rates of interest, and to provide bases for comparison of the three vaporizers. Characteristics of the three vaporizers were measured at a feed pressure and specific power of $2100 \mathrm{kPa}$ and $3.0 \mathrm{MJ} / \mathrm{kg}$, respectively, the setpoints at which all endurance tests were conducted. Performance was stable at all flow rates, although some interesting differences between the vaporizers were observed.

Figures 4 and 5 compare several steady state characteristics for the three vaporizers 
and these data are summarized in Table III. Figure 4 shows that outlet temperatures and pressures were within 10 percent of each other and the flow rates varied only about 3 percent. However, pressure drops differed substantially from one vaporizer to the next. The sand-filled vaporizer (SNO02) had the highest presure drop. Results presented in Ref. 8 showed that approximately 84 percent of the pressure drop across the SNOO2 heat exchanger was due to the packing in the outlet tube. If the design of SNOO2 were modified to eliminate the outlet tube packing, and thereby better conform to the overall designs of the two porous metal-filed vaporizers, it would have had the lowest pressure drop of the three, instead of the highest. This indicates that the sand filling had the highest porosity of the vaporizer fillings tested.

Figure 5 contrasts the heater and heat exchanger temperatures of the three vaporizers. Heater temperatures for SNO04 and SNO05 were 200 to $300^{\circ} \mathrm{C}$ higher than for SN002. This was disappointing, since one design goal for these vaporizers was to reduced heater temperatures substantially from values measured during Ref. 7 work. The cause of the elevated heater temperatures was believed to be insufficient contact between the heaters and the inside diameters of the sintered metal packings for SN004 and SN005. This was confirmed during post-test disassembly of SNOOS and this result will be discussed later. The axial heat exchanger temperature distributions for SNO04 and SNO05 also differed from expectations. Although temperature mapping of SN002 presented in Ref. 8 revealed some azimuthal nonuniformity, the bed temperatures generally progressed from subcooled or saturated near the inlet to saturated at mid-length, and on to superheated near the outlet. Temperature profiles of the metal-filled versions, however, had a maximum in the middle; In the SNOO4 case, this mid-length temperature was over $200{ }^{\circ} \mathrm{C}$ above saturation. Given the uncertainties in thermal contact resistance between the heater and porous metal packings in $\mathrm{SNOO4}$ and SN005, the heat exchanger temperatures must be regarded as highly localized, and not representative of the bulk fluid temperatures at their respective axial stations. Additional thermocouples in subsequent versions of these vaporizers would provide insight into the integrity of the heater-to-heat exchanger packing contact.

\section{Gravity Sensitivity}

Previous tests of $\mathrm{SNOO2}^{8}$ showed that insensitivity to orientation with respect to gravity in ground tests was a fair indicator of low-gravity compatibility. During those tests the impacts of changes in orientation on flow rate, outlet conditions, and temperature distribution of $\mathrm{SNO} 22$ were 
insignificant. Results presented in figures 6 and 7 show that SN004, filled with sintered metal of $10 \mu \mathrm{m}$ pore size, was similarly unaffected by rotation about a horizontal axis normal to its own. This indicates that SN004 was probably compatible with lowgravity environments.

However, SNOO5 (Figs. 8 and 9), with its $60-\mu \mathrm{m}$ pore size, did show some sensitivity to orientation with respect to gravity. Impacts on the outlet pressure and temperature were about 10 percent, but the flow rate showed no sensitivity to orientation. Changes in the heater temperature were about 5 percent of nominal, and the heat exchanger temperature near the inlet was not affected. On the other hand, the heat exchanger temperatures at mid-length and near the outlet ( $T_{b 2}$ and $T_{b 3}$ in Fig. 2) decreased sharply when the vaporizer was moved from the horizontal to the inverted (upward flow) position. Responses of $T_{b 2}$ and $T_{b 3}$ to the initial change from the upright to the horizontal position were small and shortlived, and all temperatures returned to within small fractions of their original values when SN005 was finally returned to the upright position. The reasons for the observed behavior of the heat exchanger temperatures are not known. If liquid were being pulled from the downstream end toward the inlet as the vaporizer was inverted, the downstream heat exchanger temperatures would be expected to increase, not decrease. Changes in heaterto-heat exchanger packing contact resistance distribution could have caused the observed changes. Additional temperature data are required to fully explain the observed behavior.

Although the temperature distribution within SNO05 was sensitive to orientation with respect to gravity, the impacts on outlet conditions and flow rate were not large compared to nominal values. The observed sensitivities to orientation did not render SNO05 unstable at any time. Therefore, it is likely that SNO05 would have functioned stably in low-gravity, although the steady state characteristics of such operation cannot be precisely predicted based on the ground test data. Additional tests of a duplicate of SNO05 would be valuable to evaluate whether or not these sensitivities resulted from a fabrication anomaly.

\section{Water Analyses}

As mentioned previously, water samples were obtained from the outlet of the deionization system and the inlet of the water vaporizer and analyzed for $\mathrm{pH}$, conductivity, and concentrations of iodine and selected metals. Results of these analyses showed that the deinoization system effluent contained no detectable quantities of chromium, copper, nickel, or iron (the most common elements of the materials used for the test apparatus feed 
system). About $0.16 \mathrm{ppm}$ of copper were found in the sample obtained from the vaporizer inlet. This impurity was probably leached from a piece of copper tubing used to connect the deionization system to the water reservoir. The other three metals were not detected at the vaporizer inlet. Conductivity increased slightly as the liquid passed through the feed system, from about $1 \mu$ mho-cm to just over $6 \mu$ mho-cm, most likely due to the increased copper content. Most surprising was the near total absence of iodine in the water reaching the vaporizer inlet. A microbial check valve downstream of the deionization system was supposed to add about $4 \mathrm{ppm}$ iodine to the feed water. However, only $0.2 \mathrm{ppm}$ iodine was found at the vaporizer inlet. Additional tests are required to identify and correct the cause of this finding.

\section{SN002 Endurance Test}

Figures 10 and 11 show the histories of several critical operating parameters monitored during the endurance test of SN002. This test was terminated after just $38 \mathrm{~h}$ due to a 147 percent increase in pressure drop (Fig. 11) which resulted in a reduction in flow rate from $205 \times 10^{-6}$ to $181 \times 10^{-6} \mathrm{~kg} / \mathrm{s}$. The general decreasing trends in heater temperature and outlet conditions shown in Fig. 10 resulted primarily from the gradual decrease in flow rate, with its associated decrease in input power. The short-term variations in outlet temperature, which were on the order of 10 percent of nominal values, indicate that similar uncertainties in the steady state temperatures reported herein (Table III and Figs. 4 and 5) and elsewhere (e.g., Ref. 8) must be assumed.

Post-test disassembly and inspection of SNOO2 revealed that the screen pack outlet filter was clear. This meant that the cause of the observed increase in pressure drop was embedded in the sand packing. Movement of the gas phase through the heat exchanger packing is responsible for most of the vaporizer pressure drop due to the substantial decrease in density as the liquid vaporizes. Clogging of the upstream end of the heat exchanger, where the flow stream is all or mostly liquid, would cause some increase in pressure drop. However, this would most likely be small compared to the pressure drop through regions where the fluid was mostly vapor. Therefore, clogging of the heat exchanger packing in the downstream end was believed to be the most likely cause of the increase in SNOO2 pressure drop observed. A sample of sand retrieved from the $T_{b 1}$ thermocouple port (near the inlet) had a dark orange color, as compared to the light tan color of the fresh sand used to fill SNOO2. A sample from the $T_{b 3}$ port was also darkened, but much less so than the upstream sample. The downstream sample was also more difficult to pour through the thermocouple fitting than the upstream sample, suggesting that 
some binding between the granules near the outlet of the heat exchanger had occurred.

The heat exchanger of $\mathrm{SNOO2}$ was sectioned to allow inspection of the internal surfaces. The inner surface of the shell had no noticable deposits of any kind. However, large areas of the heater were covered by a layer of sand, bonded to the inconel heater sheath. Near the inlet the deposits were dark orange in color, much like the sand sample obtained from the $T_{b 1}$ thermocouple port. Toward the middle of the heater the deposits were green in color, like copper oxide. The surface of the sintered stainless steel inlet filter was covered by a chalky orange deposit which was believed to be rust.

Results of ICP emission spectroscopy of a sample of the as-received sand used to fill SN002 revealed that it was nearly pure silica, with some excess silicon present in an unknown form. Analysis of the post-test sample obtained from the upstream end of SNO02 indicated about 1 percent by mass of aluminum and sodium. The sources of these impurities are unknown. No aluminum or sodium were found in the downstream sand sample, and a slight decrease in the silicon content was measured.

The observations made during the sampling of the sand and disassembly of $\mathrm{SNOO2}$ suggested that some corrosion of the inlet filter occurred due to oxygen dissolved in the feed water. Copper which entered the vaporizer in the feed water appeared to have reacted with the heater surface, leaving a layer of oxide. Additional analyses of the heater surface are required to confirm this. Sand granules in the downstream end of the heat exchanger seemed to have clumped together, as evidenced by the hard deposits found on the heater surface and the difficulty experienced in removing the sand sample from the downstream thermocouple port. Unfortunately, the elemental analyses of the sand samples shed little light on the mechanism by which SNOO2 clogged. It was concluded that sand was not likely a desirable filling for resistojet water vaporizers.

\section{SN005 Endurance Test}

The vaporizer filled with $60-\mu \mathrm{m}$ sintered stainless steel (SNO05) completed a test of $500 \mathrm{~h}$ and 250 thermal cycles. Figures 12 and 13 show the histories of several critical operating parameters during that test. The heater temperature decreased only slightly during the course of the test. Cycle-to-cycle variations in outlet temperature similar to those exhibited by SNO02 were observed, with corresponding responses in outlet pressure. Overall, the SN005 pressure drop rose by about 79 percent during $500 \mathrm{~h}$, which was substantially lower than for SNO02. No significant variation in flow rate occurred. 
Following the endurance test, the heat exchanger shell of SNO05 was sectioned to permit removal of the porous metal filling and heater. The heater withdrew easily from its bore in the porous metal packing, confirming earlier suspicions that thermal contact between these parts was poor. The outer and inner diameters of the porous metal annulus were generally smooth, with only a few small holes leading to the interior. This was because this part was fabricated from a larger rod of sintered stainless steel, and the machining process smeared closed most of the pores on the outer and inner diameters. Therefore the packing looked much like an ordinary metal tube, except for the open pores on the inlet and outlet ends. Deposits of a red-orange powder covered the porous inlet face uniformly. Similar deposits covered the heater surface within about $0.5 \mathrm{~cm}$ of the inlet end of the heat exchanger. Results of energy-dispersive X-ray (EDAX) analyses of these deposits detected significant concentrations of iron and oxygen, suggesting that the deposits were rust. No such deposits were seen on the outlet face. Rust deposits were found on the smooth outer surface of the porous metal packing, although they were not uniformly distributed. These deposits appeared streaked, with the streaks initiating at some of the small pores near the inlet end. These deposits indicated that rust was formed by reaction of the sintered metal packing with oxygen dissolved in the water (recall that the water source was not degassed). Rust particles could then have collected in the packing, clogging the pores and causing the resistance to flow through the packing to increase. To investigate this hypothesis, the sintered metal packing was sectioned for analysis just downstream of the $T_{b} 1$ thermocouple and just upstream of the $T_{b 3}$ thermocouple. A portion of each sample was analysed for elemental composition by ICP emission spectroscopy. No significant variations in composition between the two axial stations were measured. This suggested that any rust formed internal to the porous packing did not migrate downstream, but remained in place. The surfaces of the sections were ground and polished for analysis by secondary electron emission. Unfortunately, the results of these analyses were not available as of this writing. An additional test of an identical vaporizer using degassed feed water should be conducted to determine if the presence of free oxygen caused the rust formation.

\section{SNO04 Endurance Test}

The histories of several operating parameters during the endurance test of the $10 \mu \mathrm{m}$ sintered metal-filled vaporizer (SN004) are presented in Figs. 14 and 15. This test is ongoing, having completed 300 $\mathrm{h}$ and 150 thermal cycles to date. The heater temperature is decreasing steadily, and at a greater rate than was observed for SN005. 
The outlet temperature, however, has varied less than during the $\mathrm{SNOO2}$ and SN005 tests. The flow rate and outlet pressure have been very steady, except for the period between 220 and $240 \mathrm{~h}$, when the pressurant supply was depleted. This resulted in a reduction in the feed pressure applied to the water reservoir. Surprisingly, the rate of increase in pressure drop across SN004, with its smaller pore size, has been lower than for SN005. The increase in pressure drop has also been asymptotic, with no significant changes measured during the last $50 \mathrm{~h}$ of testing.

Clogging of the heat exchangers appears to be the most pressing life issue. However, the elevated heater temperatures observed during tests of SNOO4 and SNOO5 are also of concern because of the potential for shortened heater life at excessive temperatures. Design improvements should focus on improved heat transfer between the heaters and porous metal packings. The use of interference fits or braze joints between these components should enhance heat transfer significantly.

\section{CONCLUDING REMARKS}

Three water vaporizers were designed, built, and tested. Steady state characteristics were measured and compared, and tests for sensitivities to orientation with respect to gravity were conducted. The vaporizers were then operated for periods up to $500 \mathrm{~h}$ and 250 thermal cycles. These tests were intended as rapid first steps toward identifying and addressing life issues of water vaporizers intended for resistojet applications

Steady state characterizations revealed heater temperatures in two porous metalfilled vaporizers that were higher than expected. Inadequate thermal contact between the heater and porous heat exchanger packing was believed to have caused an excessive heater-to-heat exchanger temperature drop, and this was substantiated by post-test disassembly of one of those vaporizers. As expected, the pressure drop across the larger-pore sintered metal-filled vaporizer was lower than for the smaller-pore version. The pressure drop across the sand-filled version was between the two metal-filled versions, but would have been the lowest of the three if the design had been modified to eliminate the sand filling in the outlet tube of that version.

Previous tests of the sand-filled vaporizer demonstrated no significant sensitivities to orientation with respect to gravity in ground tests or to total acceleration in aircraft tests. Those results indicated probable compatibility of that vaporizer with a lowgravity environment. Ground tests of the $10 \mu \mathrm{m}$ sintered stainless steel-filled vaporizer demonstrated no sensitivities to orientation with respect to gravity. Some temperatures and pressures in the $60 \mu \mathrm{m}$ 
porous metal-filled vaporizer did show some sensitivities to orientation but operation was stable in all orientations.

A sand-filled vaporizer completed $38 \mathrm{~h}$ and 19 thermal cycles before the test was terminated due to a 147 percent increase in pressure drop. This caused the flow rate to decrease by more than 10 percent from the beginning-of-life value. A sintered stainless steel-filled vaporizer with a $60 \mu \mathrm{m}$ pore size completed a 500-h/250- thermal-cycle life test. The pressure drop across this vaporizer also increased, but only by about 79 percent. No significant change in flow rate was observed. Testing of another porous metal-filled vaporizer, with a $10 \mu \mathrm{m}$ pore size, was ongoing at the time of this writing, having completed $350 \mathrm{~h}$ and 175 thermal cycles. The pressure drop across this vaporizer has increased asymptotically and at a slower rate than for the version with the $60 \mu \mathrm{m}$ pores.

Post-test disassembly and inspection of the sand-filled vaporizer revealed some discoloration of the sand near the inlet and evidence that the sand granules near the outlet had bonded together during the test. The observed increase in pressure drop was believed to have been caused by a reduction in the effective porosity of the heat exchanger packing caused by this bonding. Disassembly and inspection of the metalfilled version with the $60 \mu \mathrm{m}$ pores revealed deposits that appeared to be rust.
These are believed to have been deposited in the pores of the sintered metal packing, causing the gradual increase in pressure drop observed during the endurance test of that unit. Reaction of the metal packing with dissolved oxygen in the water is the suspected cause of the rust formation.

Further work should include degassing of the feed water to better represent the likely source of propellant aboard SSF. This could eliminate the formation of rust observed during these tests, with its associated impact on vaporizer pressure drop. Alternate heat exchanger materials could also be investigated if corrosion problems persist with the $304 \mathrm{~L}$ stainless steel used in these life tests. In addition, the design of the vaporizer metal-filled should be modified to enhance heat transfer between the heater and heat exchanger packing. Additional tests using sand fillings are not recommended, due to the tendency of the granules to bond together and increase the resistance to flow.

\section{ACKNOWLEDGMENTS}

The authors gratefully acknowledge the contributions of Frances A. Archer, Patricia O. Dickerson, and Wai C. Wan of the NASA Lewis Research Center, who conducted a variety of materials analyses which yielded valuable insight into the phenomena observed during this program. Special thanks also to Michael R. Pastel 
and Jerry C. Pobuda of Calspan Corporation for their assistance with the preparation of the endurance test hardware.

\section{REFERENCES}

1. Greco, R. V., et al., "Development of

a Biowaste Resistojet Propulsion System Propellant Management and Control System," AIAA 72-448, April 1972.

2. Louviere, A. J., et al., "WaterPropellant Resistojets for ManTended Platforms," IAF-87-259, October 1987.

3. Zimmermann, F. and France, C., "Secondary Propulsion System Options for Space Station Freedom," AIAA 92-3852, July 1992.

4. Phillips, D. G., "Technology Development of a Biowaste Resistojet, Volume 2," NASA CR112150, June 1972.

5. Anon., "Development of a Water Vaporizer for Resistojet Applications: Final Report," The Marquardt Company Report S-1244, November 1972.

6. Morren, W. E. and Stone, J. R., "Development of a Liquid-Fed Water
Resistojet," AIAA 88-3288, July 1988.

7. Morren, W. E., "Preliminary Characterizations of a Water Vaporizer for Resistojet Applications," AIAA 93-3533, July 1992.

8. Morren, W. E., "Gravity Sensitivity of a Resistojet Water Vaporizer," AIAA 93-2402, June 1993.

9. Gruber, R. P., "DC Power Control for a Liquid-Fed Resistojet," IEPC 88-045, October 1988.

10. Pugmire, T. K., et al.," A $10,000-$ Hour Life Multipropellant Engine for Space Station Applications," AIAA 86-1403, June 1986. 
Table I. Comparison of Selected Vaporizer Design Features

$\mathrm{SNO02}$

Packing

Flow Path Shape

Length/Area

No. of Feed Tubes

No. of Thermocouples

Inlet Filter

Outlet Filter sand

annulus and tube in series

12.2

4

12

sintered stainless steel, type 304L, $5 \mu \mathrm{m}$ pore size

stainless steel screen, 4 layers 5 -mesh and 1 layer 50-mesh
SN004

SN005

sintered stainless sintered stainless steel, type 304L, steel, type 304L, $10 \mu \mathrm{m}$ pore size $\quad 60 \mu \mathrm{m}$ pore size

annulus

annulus

3.84

1

3

none

none
3.84

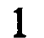

3

none

none 
Table II. Vaporizer Operating Parameters Monitored

\begin{tabular}{|c|c|c|}
\hline Parameter & Symbol & Technique \\
\hline Voltage, V & $V_{h}$ & Voltage Divider \\
\hline Current, A & $\mathbf{I}_{\mathbf{b}}$ & Hall-Effect Probe \\
\hline Feed Pressure, $\mathrm{kPa}$ & $\mathbf{P}_{\mathbf{f}}$ & $\begin{array}{l}\text { Capacitance Pressure } \\
\text { Transducer }\end{array}$ \\
\hline Fluid Resistor Pressure Drop, $\mathrm{kPa}$ & $\Delta P$ & $\begin{array}{l}\text { Strain Gauge Pressure } \\
\text { Transducer }\end{array}$ \\
\hline Inlet Pressure, $\mathrm{kPa}$ & $P_{i}$ & $\begin{array}{l}\text { Capacitance Pressure } \\
\text { Transducer }\end{array}$ \\
\hline Inlet Temperature, ${ }^{\circ} \mathrm{C}$ & $\mathbf{T}_{\mathbf{i}}$ & Type K Thermocouple \\
\hline Heater Temperature, ${ }^{\circ} \mathrm{C}$ & $T_{h}$ & Type K Thermocouple \\
\hline Inlet Bed Temperatures, ${ }^{\circ} \mathrm{C}$ & $\mathrm{T}_{\mathrm{b} 1}, \mathrm{~T}_{\mathrm{b} 4}, \mathrm{~T}_{\mathrm{b} 7}, \mathrm{~T}_{\mathrm{b} 10}$ & Type K Thermocouple \\
\hline Midpoint Bed Temperatures, ${ }^{\circ} \mathrm{C}$ & $\mathrm{T}_{\mathrm{b} 2}, \mathrm{~T}_{\mathrm{b5}}, \mathrm{T}_{\mathrm{b} 8}, \mathrm{~T}_{\mathrm{b} 11}$ & Type K Thermocouple \\
\hline Outlet Bed Temperatures, ${ }^{\circ} \mathrm{C}$ & $\mathrm{T}_{\mathrm{b} 3}, \mathrm{~T}_{\mathrm{b} 6}, \mathrm{~T}_{\mathrm{b} 9}, \mathrm{~T}_{\mathrm{b} 12}$ & Type K Thermocouple \\
\hline Outlet Temperature, ${ }^{\circ} \mathrm{C}$ & $\mathrm{T}_{\mathrm{o}}$ & Type K Thermocouple \\
\hline Outlet Pressure, $\mathrm{kPa}$ & $P_{0}$ & $\begin{array}{l}\text { Capacitance Pressure } \\
\text { Transducer }\end{array}$ \\
\hline Power, W & $\mathrm{P}_{\mathrm{e}}$ & derived \\
\hline Flow Rate, $\mathrm{kg} / \mathrm{s}$ & $\mathrm{m}$ & derived \\
\hline Specific Power, MJ/kg & $P_{\text {sp }}$ & derived \\
\hline
\end{tabular}


Table III. Vaporizer Steady Operating Characteristics

$\begin{array}{lccc} & \text { SNO02 } & \text { SNO04 } & \text { SNO05 } \\ \mathrm{P}_{\mathrm{f}}, \mathrm{kPa} & 2082 & 2123 & 2068 \\ \mathrm{~m} \times 106, \mathrm{~kg} / \mathrm{s} & 203 & 208 & 209 \\ \mathrm{P}_{\mathrm{sp}}, \mathrm{MJ} / \mathrm{kg} & 3.02 & 2.99 & 2.99 \\ \mathrm{P}_{\mathrm{i}}, \mathrm{kPa} & 682 & 633 & 579 \\ \mathrm{P}_{\mathrm{b}}, \mathrm{kPa} & 462 & 471 & 506 \\ \mathrm{~T}_{\mathrm{i}},{ }^{\circ} \mathrm{C} & 27 & 27 & 26 \\ \mathrm{~T}_{\mathrm{o}},{ }^{\circ} \mathrm{C} & 232 & 215 & 224 \\ \mathrm{~T}_{\mathrm{b}},{ }^{\circ} \mathrm{C} & 261 & 583 & 565 \\ \mathrm{~T}_{\mathrm{b} 1},{ }^{\circ} \mathrm{C} & 160 & 124 & 118 \\ \mathrm{~T}_{\mathrm{b} 2},{ }^{\circ} \mathrm{C} & 161 & 333 & 194 \\ \mathrm{~T}_{\mathrm{b} 3},{ }^{\circ} \mathrm{C} & 194 & 160 & 187 \\ \mathrm{~T}_{\mathrm{b} 4},{ }^{\circ} \mathrm{C} & 107 & - & - \\ \mathrm{T}_{\mathrm{b} 5},{ }^{\circ} \mathrm{C} & 160 & - & - \\ \mathrm{T}_{\mathrm{b} 6},{ }^{\circ} \mathrm{C} & 216 & - & - \\ \mathrm{T}_{\mathrm{b} 7},{ }^{\circ} \mathrm{C} & 107 & - & - \\ \mathrm{T}_{\mathrm{b} 8},{ }^{\circ} \mathrm{C} & 158 & - & - \\ \mathrm{T}_{\mathrm{b} 9},{ }^{\circ} \mathrm{C} & 184 & - & - \\ \mathrm{T}_{\mathrm{b} 10},{ }^{\circ} \mathrm{C} & 156 & - & - \\ \mathrm{T}_{\mathrm{b} 11},{ }^{\circ} \mathrm{C} & 160 & - & - \\ \mathrm{T}_{\mathrm{b} 12},{ }^{\circ} \mathrm{C} & 204 & - & - \\ & & & \end{array}$




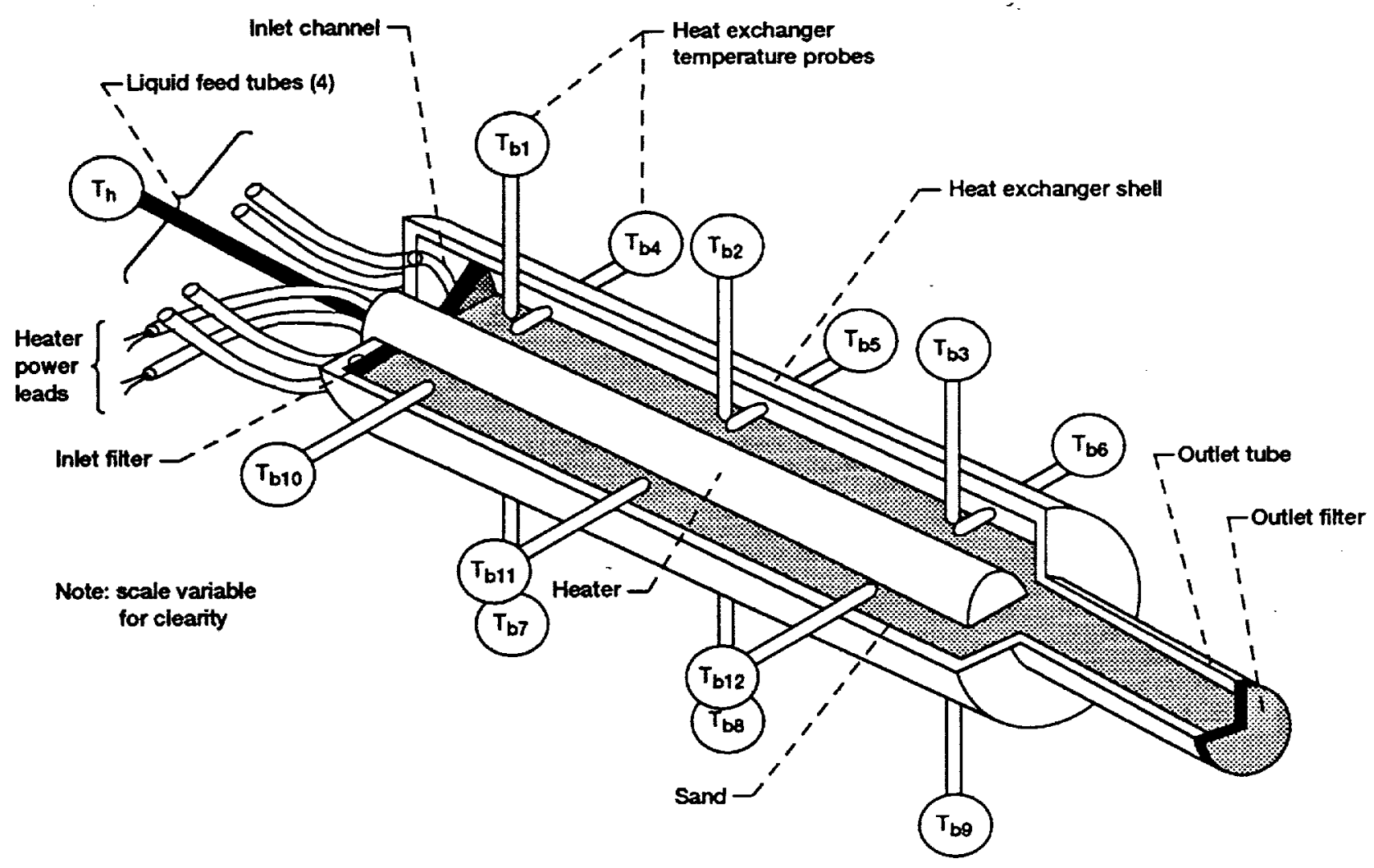

Figure 1.-Sectional view of sand-packed water vaporizer (Ref. 8).

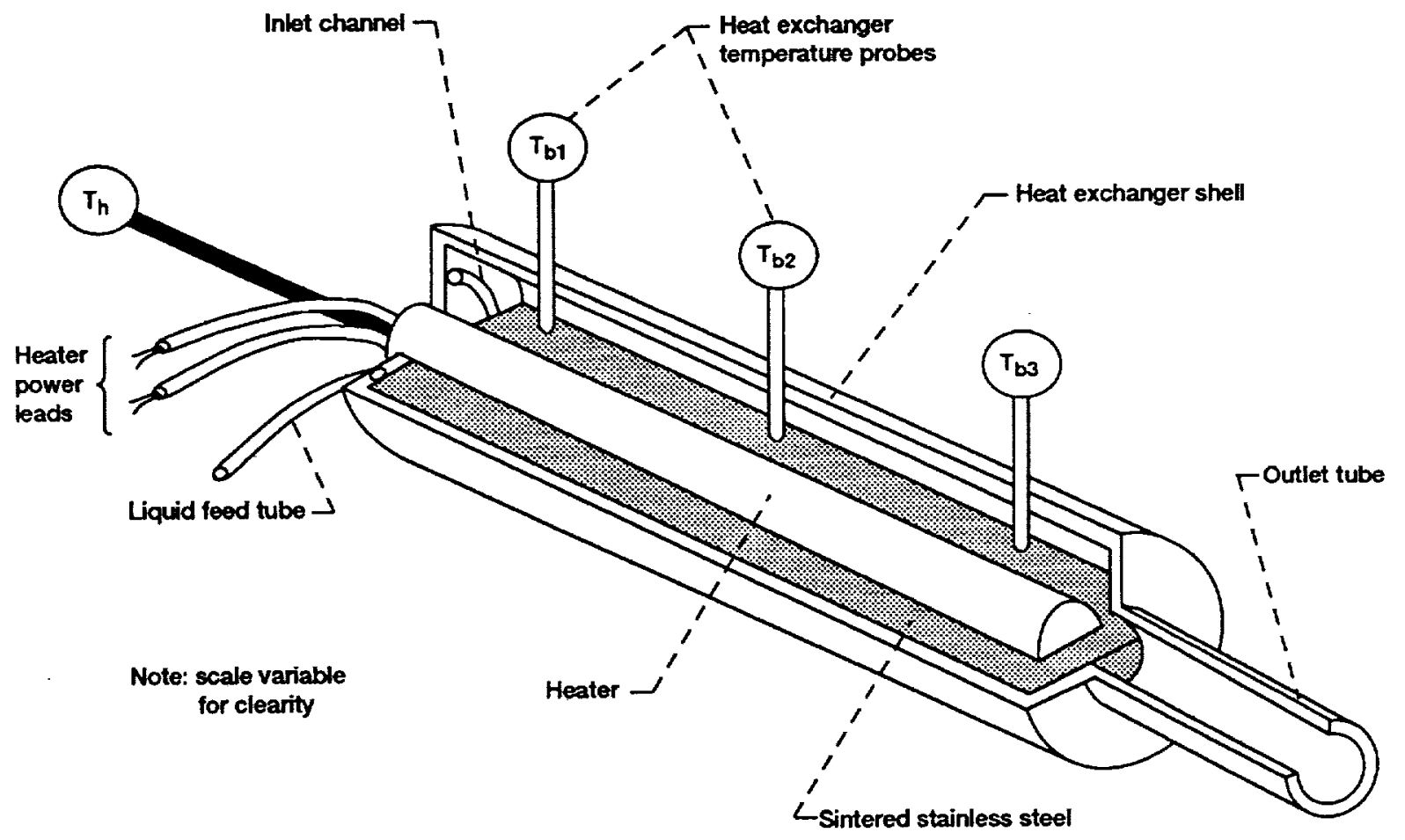

Figure 2.-Sectional view of sintered metal-packed water vaporizer. 


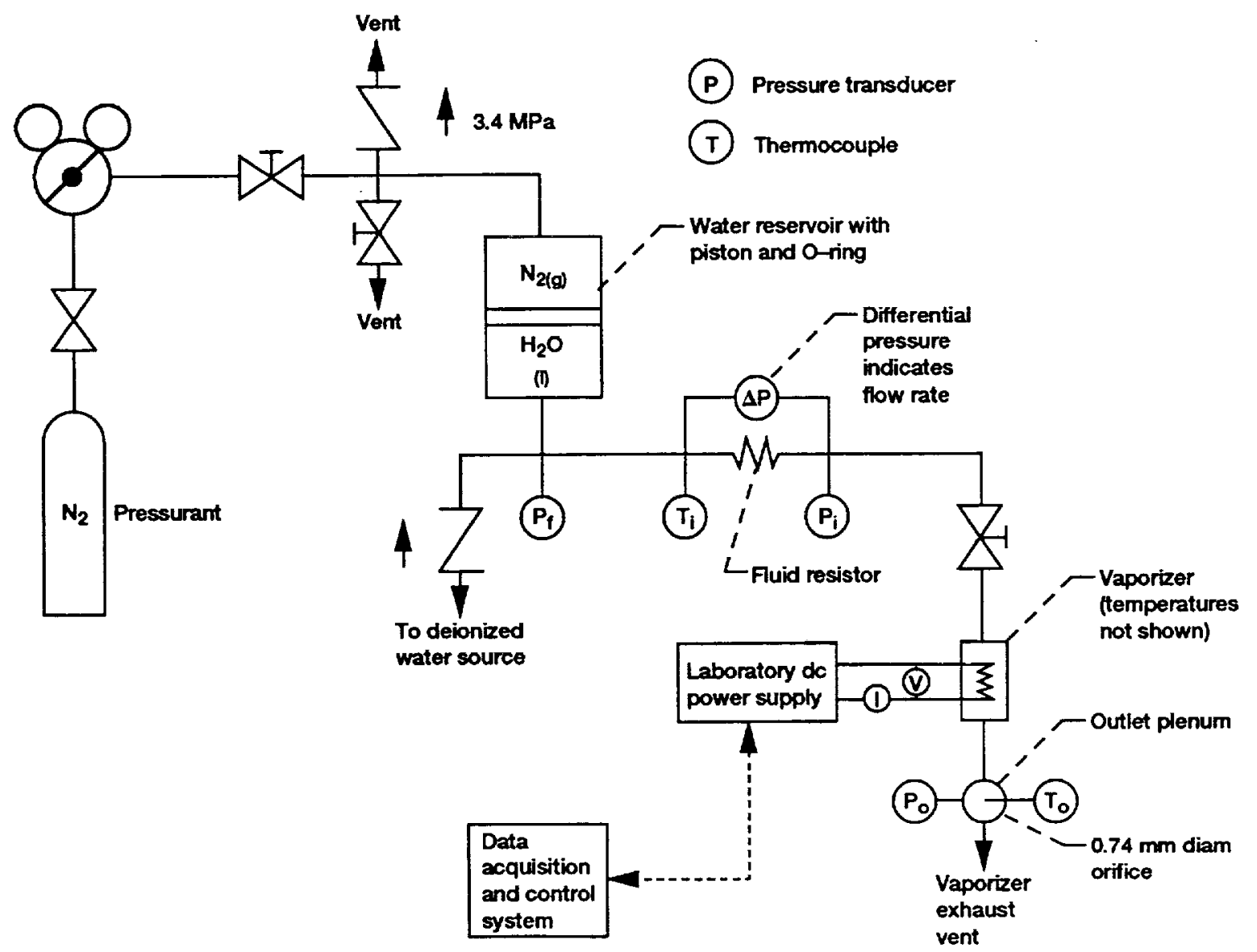

Figure 3.-Water vaporizer test apparatus schematic. 


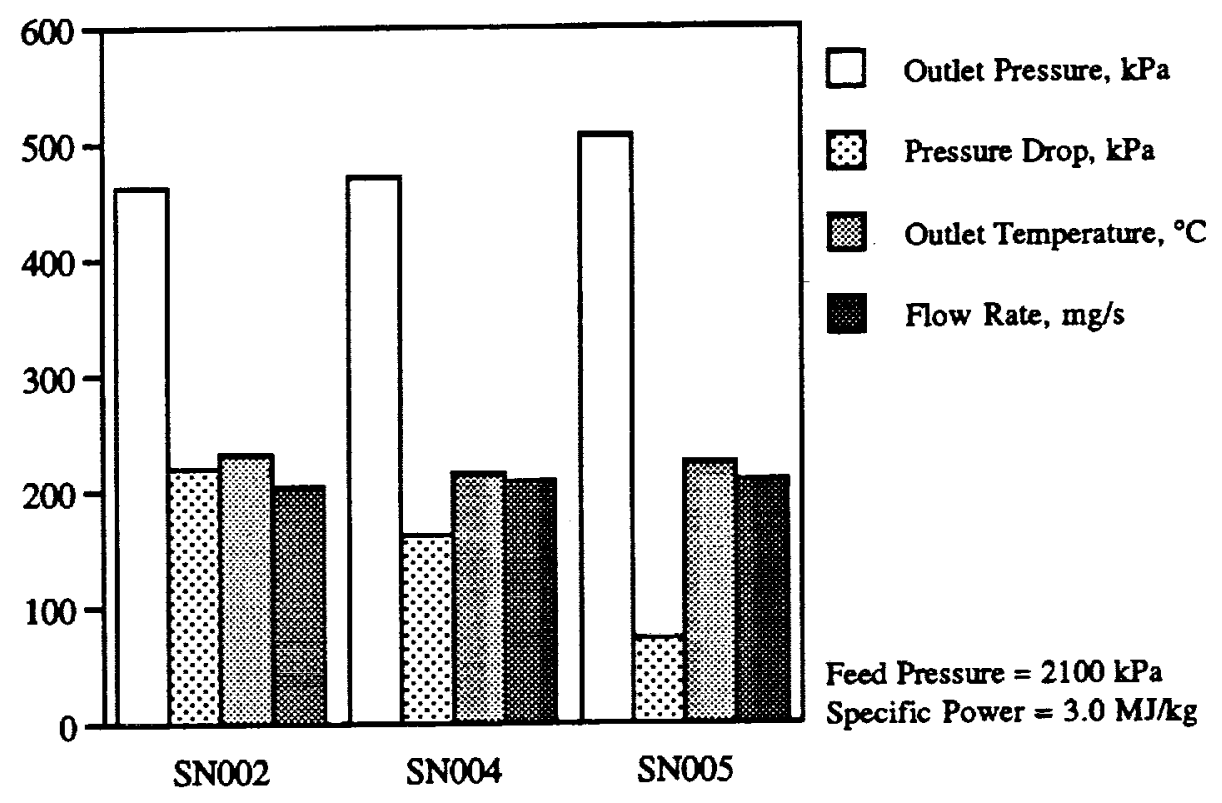

Figure 4. Flow Rates, Outlet Conditions, and Pressure

Drops for Three Packed-Bed Water Vaporizers

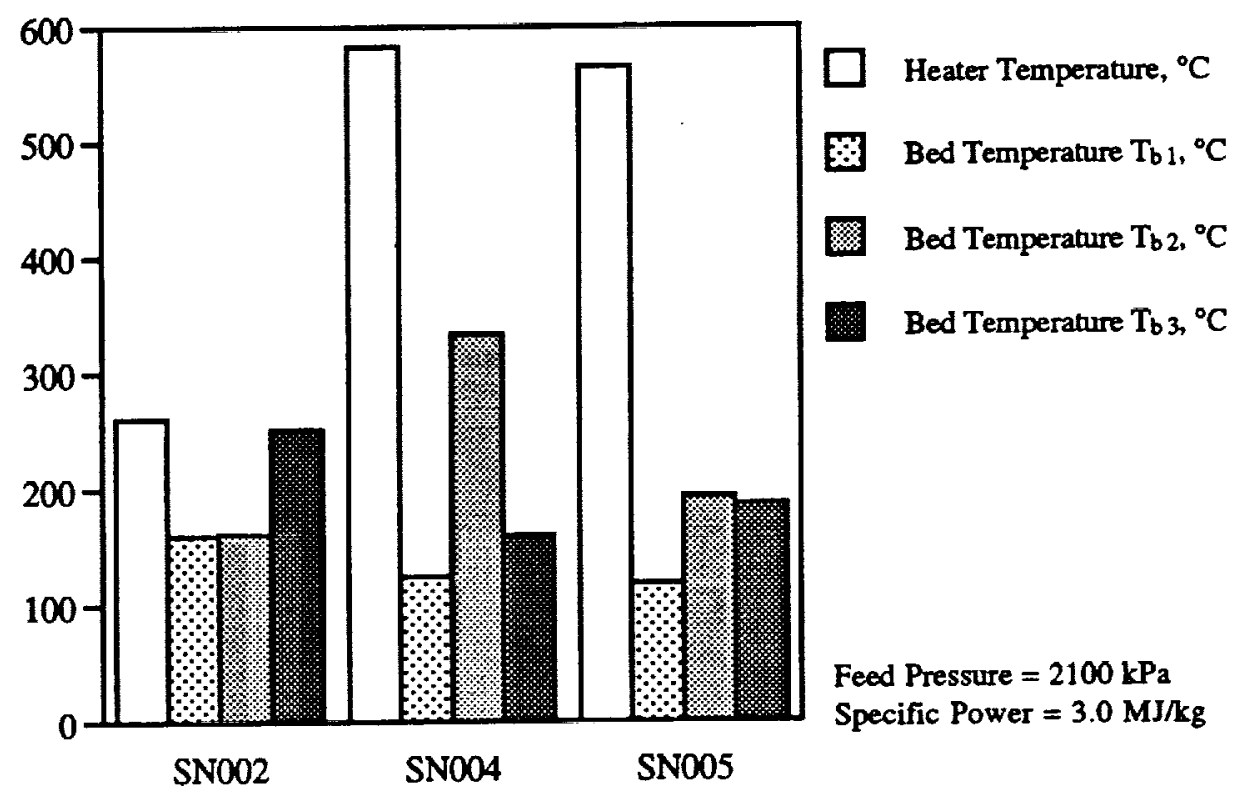

Figure 5. Steady State Heater and Heat Exchanger Temperatures for Three Packed-Bed Water Vaporizers 


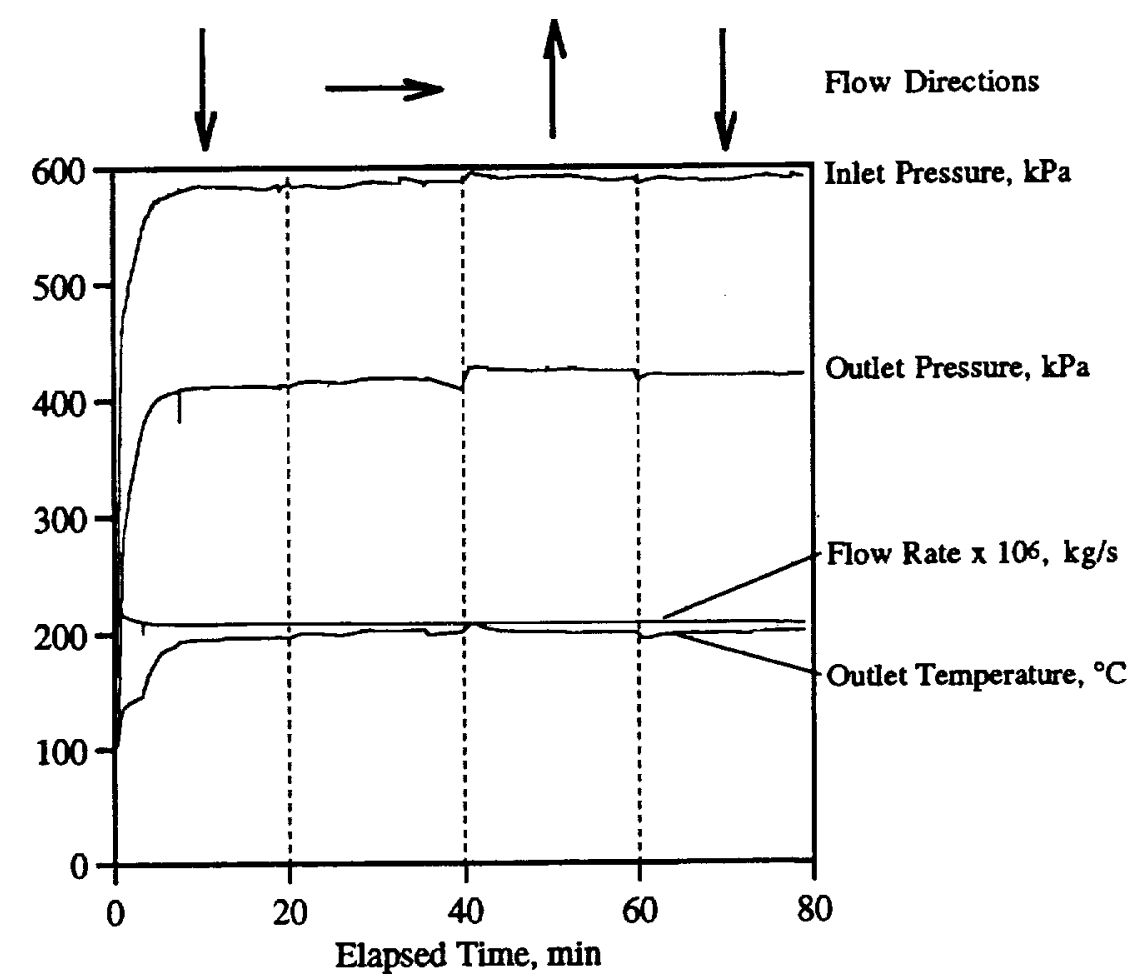

Figure 6. Responses of Flow Rate and Inlet and Outlet Conditions to Changes in Orientation With Respect to Gravity for $10 \mu \mathrm{m}$ Sintered Metal-Filled Water Vaporizer (SNO04)

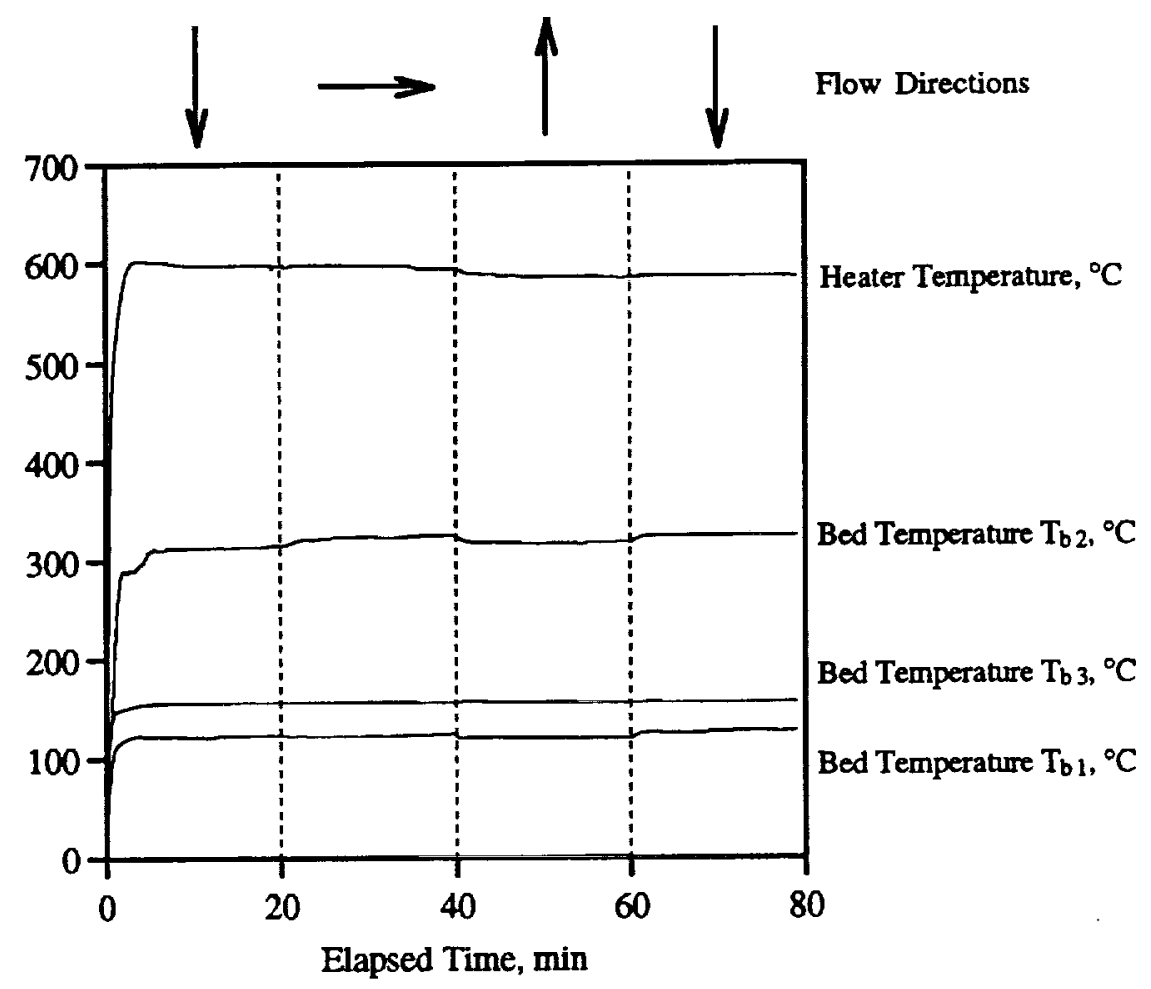

Figure 7. Responses of Heater and Heat Exchanger Temperatures to Changes in Orientation With Respect to Gravity for $10 \mu \mathrm{m}$ Sintered Metal-Filled Water Vaporizer (SNO04) 


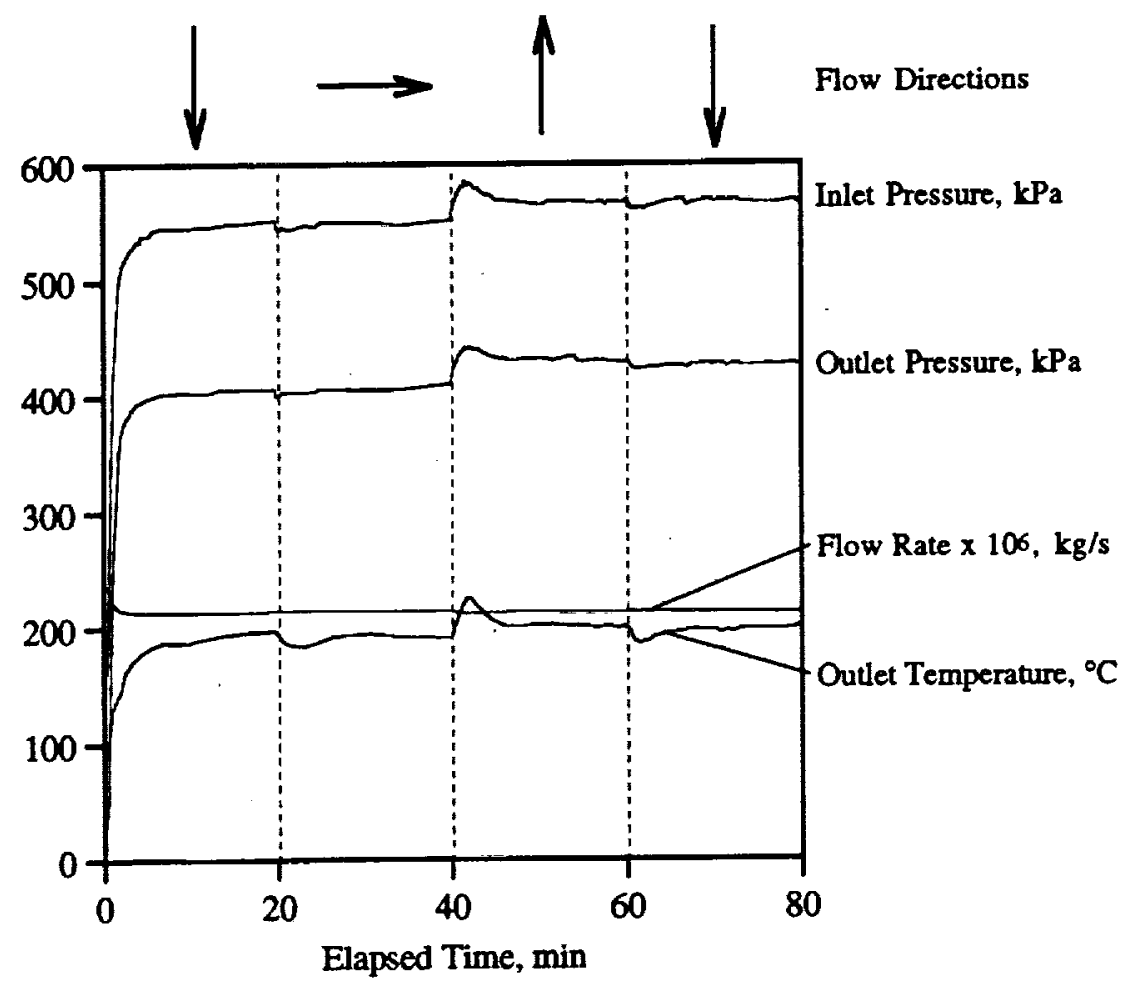

Figure 8. Responses of Flow Rate and Inlet and Outlet Conditions to Changes in Orientation With Respect to Gravity for $60 \mu \mathrm{m}$ Sintered Metal-Filled Water Vaporizer (SN005)

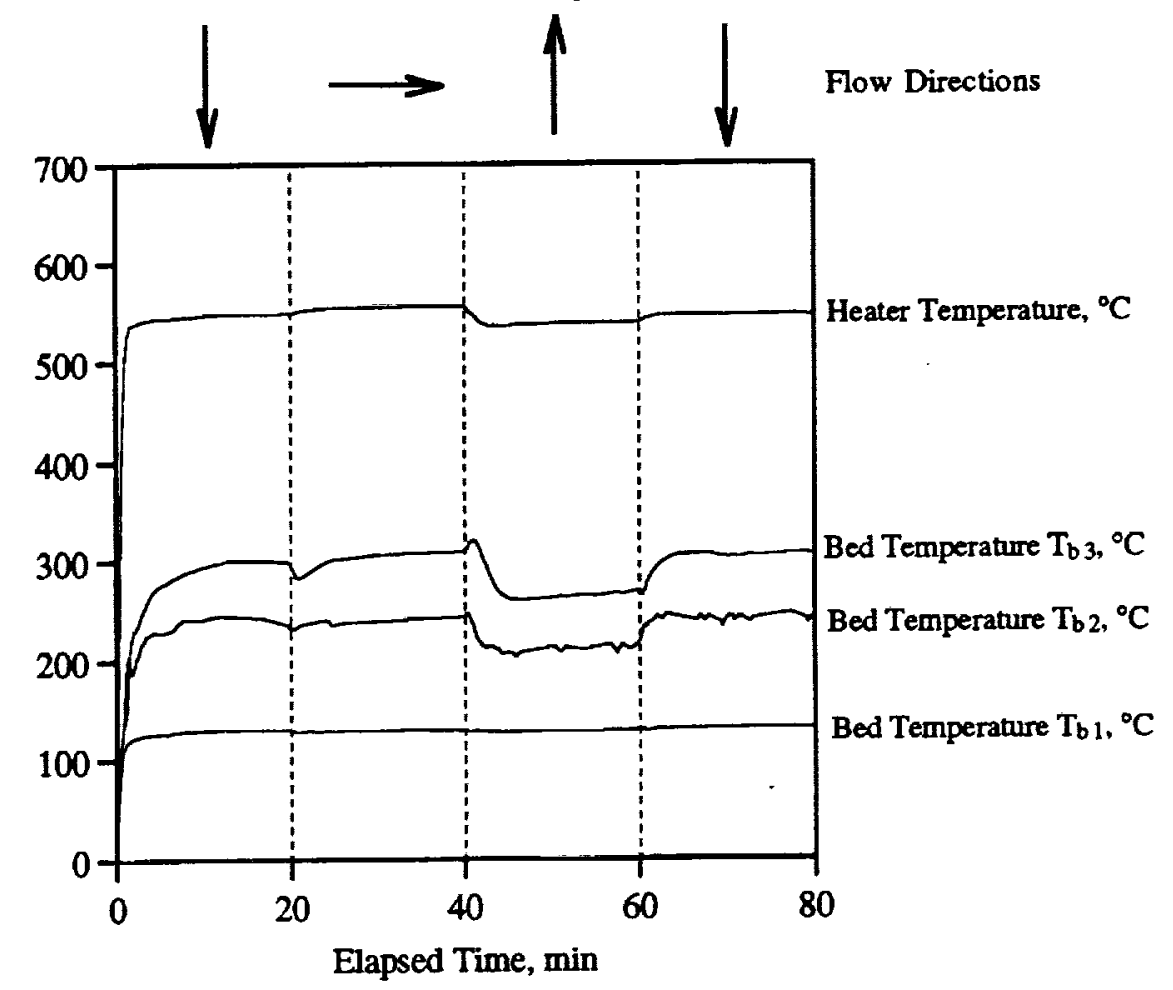

Figure 9. Responses of Heater and Heat Exchanger Temperatures to Changes in Orientation With Respect to Gravity for $60 \mu \mathrm{m}$ Sintered Metal-Filled Water Vaporizer (SNO05) 


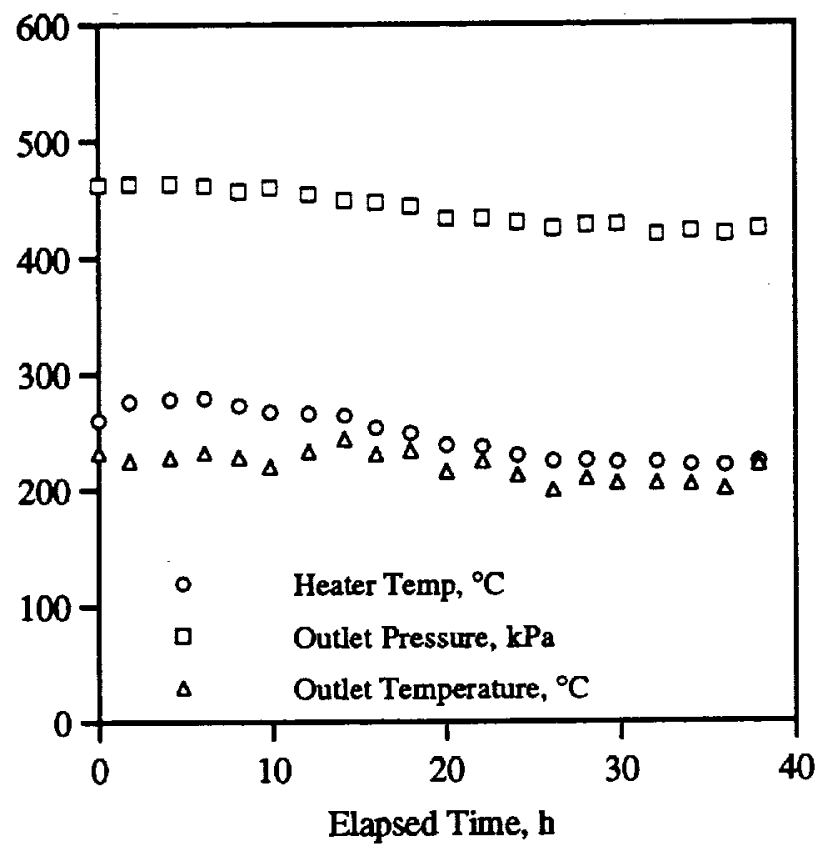

Figure 10. Outlet Condition and Heater Temperature Histories for Sand-Filled Water Vaporizer (SNO02)

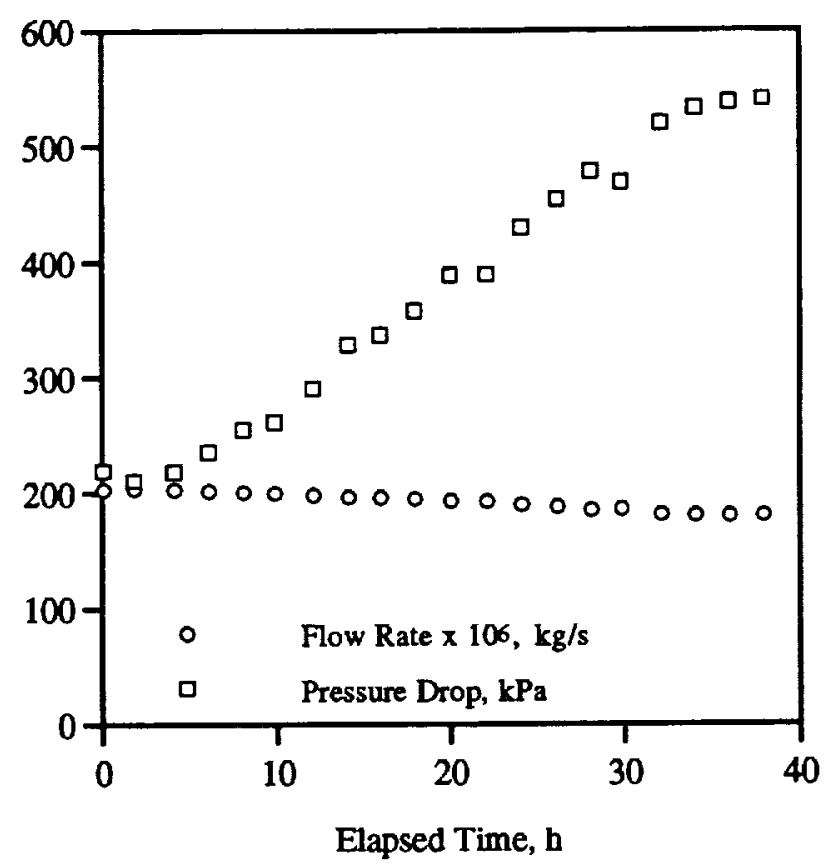

Figure 11. Pressure Drop and Flow Rate Histories for Sand-Filled Water Vaporizer (SNO02) 


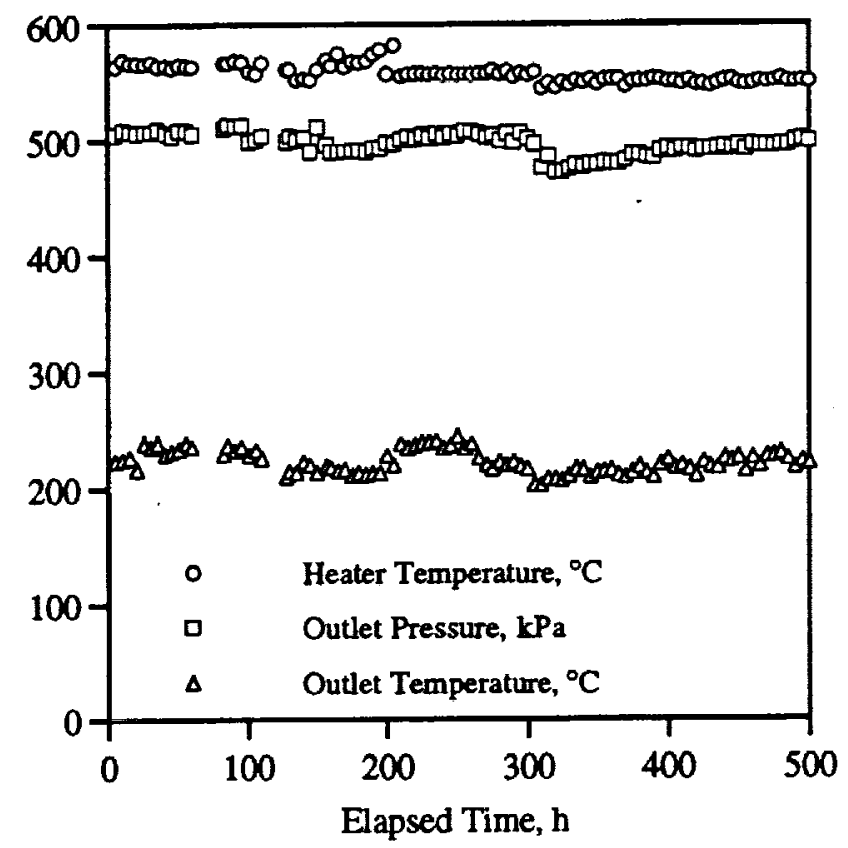

Figure 12. Outlet Condition and Heater Temperature Histories for $60 \mu \mathrm{m}$ Sintered Metal-Filled Water Vaporizer (SNO05)

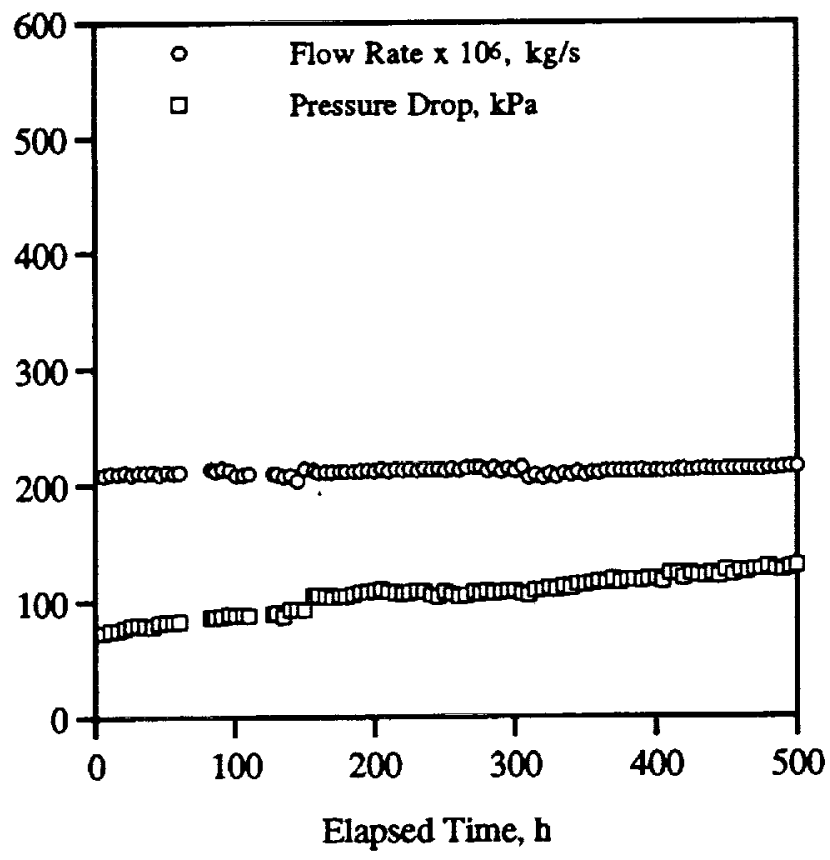

Figure 13. Flow Rate and Pressure Drop Histories for 60 $\mu \mathrm{m}$ Sintered Metal-Filled Water Vaporizer (SNO05) 


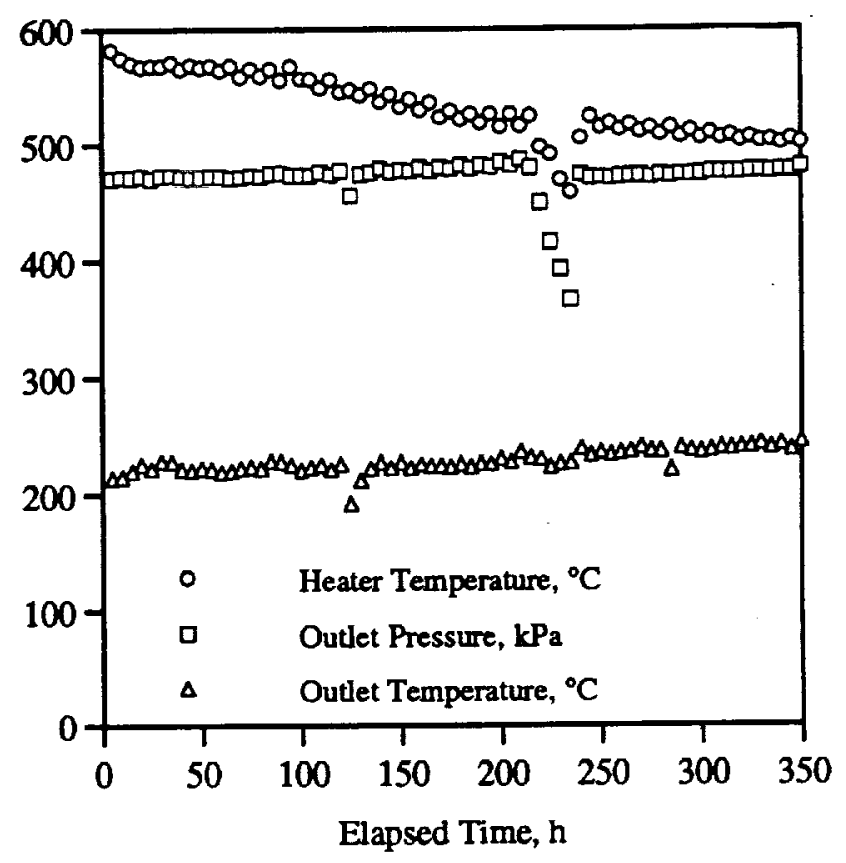

Figure 14. Outlet Condition and Heater Temperature Histories for $10 \mu \mathrm{m}$ Sintered Metal-Filled Water Vaporizer

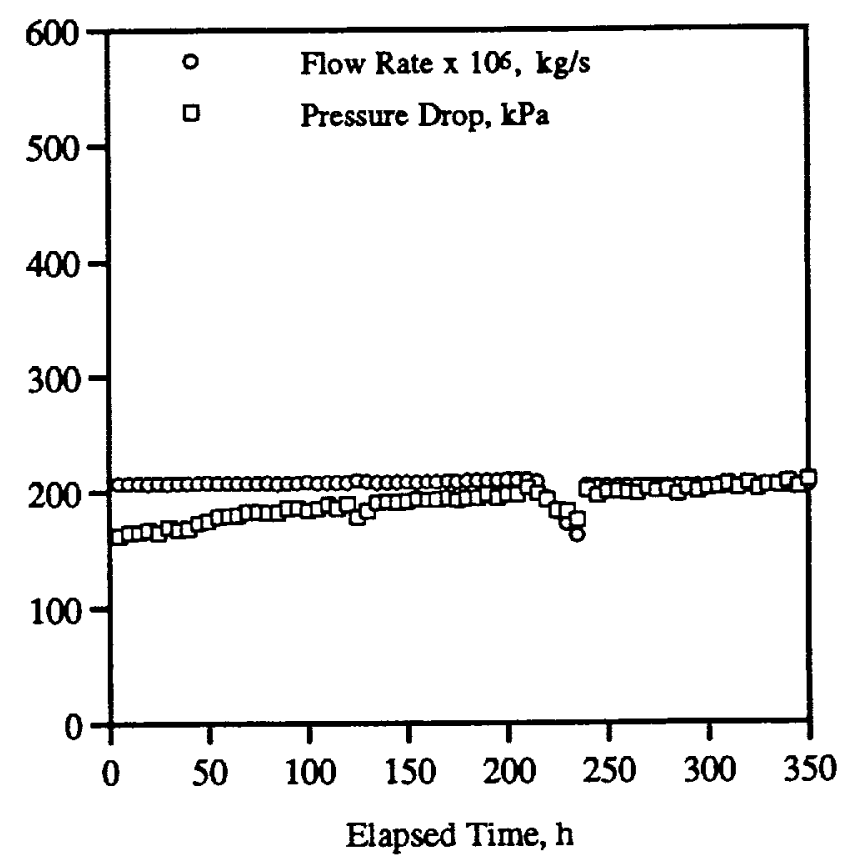

Figure 15. Pressure Drop and Flow Rate Histories for 10 $\mu \mathrm{m}$ Sintered Metal-Filled Water Vaporizer 
Public reporting burden for this collection of information is estimated to average 1 hour per response, Including the time for reviewing instructions, searching existing data sources, gathering and maintaining the data needed, and completing and reviewing the collection of information. Send comments regarding this burden estimate or any other aspect of this collection of information, including suggestions for reducing this burden, to Washington Headquarters Services, Directorate lor Imformalion Operations and Roports, $1215 \mathrm{~J}^{2}$, Davis Highway. Suite 1204, Arlington, VA 22202-4302, and to the Office of Management and Budget, Paperwork Reduction Project (0704-0188), Washington, DC 20503.

\begin{tabular}{|l|l|l|}
\hline 1. AGENCY USE OMLY (Leave blank) & 2. REPORT DATE & 3. REPORT TYPE AND DATES COVERED
\end{tabular}

TITE AND SUBTITLE

June 1993

Technical Memorandum

Preliminary Endurance Tests of Water Vaporizers for Resistojet Applications

6. AUTHOR(S)

WU-506-42-31

W. Earl Morren and Gregory S. MacRae

7. PERforming ORGANRATION NAME(S) AND ADDRESS(ES)

8. PERFORMING ORGANIZATION REPORT MUMBER

National Aeronautics and Space Administration

Lewis Research Center

E-7871

Cleveland, Ohio 44135-3191

9. SPONSORING/MONTORING AGENCY NAME(S) AND ADORESS(ES)

National Aeronautics and Space Administration

Washington, D.C. 20546-0001

10. SPONSORINGMONITORING AGENCY REPORT NUMBER

NASA TM-106222

AIAA-93-2403

11. SUPPLEMENTARY NOTES

Prepared for the 29th Joint Propulsion Conference and Exhibit, cosponsored by the AIAA, SAE, ASME, and ASEE, Monterey, California, June 28-30, 1993. Responsible person, W. Earl Morren, (216) 433-7425.

12.. DISTRIBUTION/AYAILABILTY STATEMENT

12b. DISTAIBUTION CODE

Unclassified - Unlimited

Subject Category 20

13. ABSTRACT (Naximum 200 words)

Three water vaporizers designed for resistojet applications were built and tested for periods up to $500 \mathrm{~h}$ and 250 thermal cycles. Two of the vaporizers were not sensitive to orientation with respect to gravity, an indication of likely compatibility with low-gravity environments. Some temperatures and pressures in the third were impacted by orientation, although operation was always stable. The pressure drop across the sand-filled version increased by 147 percent in $38 \mathrm{~h}$ and 19 thermal cycles. Bonding of the sand granules in the downstream end of the heat exchanger was the suspected cause of failure of this vaporizer. Pressure drops across the two sintered stainless steel-filled versions were more gradual. One, with a pore size of $60 \mu \mathrm{m}$, showed an 80 percent increase in $500 \mathrm{~h}$ and 250 thermal cycles and another, with a $10 \mu \mathrm{m}$ pore size, showed a 29 percent increase in $350 \mathrm{~h}$ and 175 thermal cycles. Testing of the latter metal-filled vaporizer was ongoing as of this writing. Oxidation of the porous metal packing materials in these vaporizers, with subsequent deposition of oxide particles within the pores, was believed to have caused the observed increases in pressure drops.

\section{SUBJECT TERMS}

Resistojet; Water vaporizer; Low-gravity; Two-phase flow; Spacecraft propulsion

17. SECURTY CLASSIFICATION OF REPORT

Unclassified
18. SECURITY CLASSIFICATION OF THIS PAGE

Unclassified
19. SECURTY CLASSIFICATION OF ABSTRACT Unclassified 